\title{
Sustainability assessment of a micro hydropower plant in Nepal
}

\author{
Ramchandra Bhandari ${ }^{*}$, Lena Ganda Saptalena ${ }^{1}$ and Wolfgang Kusch ${ }^{2}$
}

\begin{abstract}
Background: Many rural electrification projects around the world employ micro hydropower plants (MHPs). These installations provide immediate and direct benefits to the local people. However, the sustainability of their operation in the long run remains a vital issue. Without proper sustainability assessment, the projects may face operational problems. However, to date, only a few empirical studies exist which offer tools to assess sustainability of MHP projects post-implementation. Given that every site has peculiar characteristics that could largely vary from site to site, there is a need to develop a model which could assess and compare the feasibility of the projects from the sustainability point of view before the project is implemented. For this purpose, a thorough sustainability assessment model was developed for an MHP project in a mountainous region of Nepal.

Methods: This paper presents a sustainability assessment model for micro hydropower plants. In order to collect the data necessary to run the model, different sets of questionnaires were prepared for all relevant stakeholders. The developed model was used to assess an overall sustainability of a 26-kW plant at Mahadevsthan in Dhading District of Nepal. At this site, 15 community households, a project management committee member, an operator, and three policy makers/micro hydro experts were interviewed. The indicator system developed here was finalized with the stakeholder's participation.

Results: A sustainability assessment model for the operation of micro hydropower plants in a remote rural area of Nepal was developed. Our model includes 54 assessment indicators taking into account economic, social, environmental, and technical sustainability dimensions and a scoring system (ranging from 1 to 5 , with 5 being the best). It was found that the social dimension shows the best performance with a score of 4.17 for the studied MHP, followed by environmental (3.94), economic (3.74), and technical dimensions (3.04).

Conclusions: The results show that the developed model creates a qualitative and quantitative basis for sustainability assessment of MHPs, allowing easiness for comparison of micro hydro projects, providing an effective decision-making support tool in rural electrification and development sector. The input of all stakeholders in identifying site-specific indicators that are relevant to the sustainability of the projects is crucial for minimizing biases in the assessment framework.
\end{abstract}

Keywords: Rural electrification, Indicators, Model, Hydropower

\section{Background}

The vast majority of rural population in developing countries depends on biomass as their primary fuel. In 2016, an estimated 1.1 billion (around 14\% of the world's population) still lacked access to electricity [1]. Most of those people live in remote areas that are often difficult to access and therefore to connect to national or regional power grids. Among those without electricity,

\footnotetext{
* Correspondence: ramchandra.bhandari@th-koeln.de

${ }^{1}$ Institute for Technology and Resources Management in the Tropics and Subtropics, TH Köln (University of Applied Sciences), Betzdorfer Strasse 2, 50679 Cologne, Germany

Full list of author information is available at the end of the article
}

an estimated $84 \%$ of them live in rural areas in developing countries, mostly in sub-Saharan Africa and South Asia [1, 2]. Energy is one of the basic inputs for all economic activities [3]. Per capita energy consumption is one of the major determinants as well as an indicator of economic development. Per capita energy consumption and economic growth reinforce each other in developing countries like Nepal [4]. Although electricity is not an end in itself, it is essential to facilitate social and economic activity [5].

Electrification correlates closely with key aspects of sustainable development. Expanding access to modern 
energy services for the poor is essential for achieving the Sustainable Development Goals (SDGs) (SDG 7, SDG 5, and SDG 3) set by the United Nations [6]. To build sustainable systems, the symbiotic relation between energy, development, and environmental impacts needs to be understood better [7]. Energy services for poverty reduction are less about technology and more about understanding the role that energy plays in people's lives and responding to the constraints in improving livelihoods. Energy needs should be considered within the overall context of community life, and energy policies and projects should be integrated in a holistic way with other improvement efforts relating to health, education, agriculture, and job creation. Policies, programs, and projects should start from an assessment of people's needs rather than a plan to promote a particular technology [8].

The choice of a specific energy technology for rural electrification depends on targeted country and target groups to benefit from the process. Issues of customer and load density; relative distance to the national or regional grid; landscape; availability of natural resources such as wind, sun, water, and forests; economic and financial aspects; and availability and maturity of any chosen technology, all these factors influence the decision maker in her/his choice of the technology or technology mix [9]. The impact of the electrification of rural areas should not be assessed as an independent activity, but rather, it has to be considered as one of the components of an integrated rural development program [10]. During the preparation phase of a program, it is essential to determine whether a program fits into overall national goals and objectives. Needs assessment and stakeholder analysis should be carried out [11].

Several rural electrification projects have been implemented by governmental organizations, non-governmental organizations, and private sectors for decades in many countries. Subsidy has become the default mechanism for financing such projects in most of the countries. Despite huge efforts from the implementing agencies and the advance in technologies, experiences show that these projects are not achieving their goals up to the stakeholder's expectations. Technical, economic, and social sustainability of such projects are lacking in many cases.

Nepal is the second richest country in inland water resources, with 6000 rivers with a total length of about $45,000 \mathrm{~km}$ [12]. The perennial nature of Nepali rivers and the steep gradient of the country's topography provide ideal condition for the development of hydropower projects. Studies show that the feasible hydro potential in Nepal is about $83 \mathrm{GW}$, about $42 \mathrm{GW}$ of which is considered as technically and economically viable [13]. Though Nepal has a huge potential of hydropower generation, its exploitation is very low. The annual report of Nepal Electricity Authority (NEA) shows the country's power generation from hydropower is only 652.8 MW (436.4 from the NEA hydro and 216.4 from the Independent Power Producers (IPP) hydro); additional capacities include $22 \mathrm{MW}$ thermal plants and 116.2 MW import [14]. Nepal generates almost all of its electricity from hydroelectric sources and had an electricity access rate of about $60 \%$ by 2014 [15]. The average annual population growth rate in Nepal from 2005 to 2014 was $1.1 \%$ [16]. During this same period, the overall electricity consumption increased at a rate of approximately 9\% per year [14]. Between 2005 and 2014, the peak demand has more than doubled from 557 to $1200 \mathrm{MW}$. In the same period of time, the annual electricity production increased from 2642 to 4631 GWh. Out of these, 3558 GWh have been produced domestically, while 1072 GWh have been imported from India [14]. Parajuli et al. [17] have analyzed the energy consumption projection of Nepal based on its energy consumption and macro-economic data between 1996 and 2009. In their high-growth scenario, they forecast the electricity consumption growth by tenfold in 2030 compared to the consumption in 2009, whereas in business as a usual scenario, the growth is expected to be about 3.47 times higher. Based on these figures and studies, it is clear that Nepal has been facing an energy crisis, and, at this current rate of electricity consumption and production, the situation will get worse, while at the same time the country is utilizing only $1.6 \%$ (i.e., $652.8 \mathrm{MW}$ out of $42 \mathrm{GW}$ ) of its hydropower potential capacity.

A fairly high number of development projects around the globe employ micro hydropower plants (MHPs) to provide electricity access to areas not connected to a central grid. Nepal is one of the countries where numerous (about 1287 plants with a cumulative capacity of $25 \mathrm{MW}$ as of 2012 [18]) micro hydro-based rural electrification plants have been installed for decades, and during the past one decade, this trend has been intensified. The micro hydro plants in Nepal are installed with individual capacity ranging from 5 to $100 \mathrm{~kW}$.

Despite the increasing, unmet demand in electricity and the increasing installations of small-scale renewable energy projects such as MHPs, the sustainability of the installations is still in question. MHP has been recognized as one of the important projects in alleviating poverty in rural areas of Nepal. However, to date, only a few empirical studies exist which analyze the impacts of such project on local living conditions and its sustainability post-implementation. To better understand the impacts, the sustainability, and the factors influencing sustainability of these projects, the case study presented in this paper evaluated the sustainability of an MHP project in a mountainous region in Nepal post-implementation. A thorough sustainability assessment comprising technical, social, economic, and environmental factors has been 
carried out in this work. The overall aim of this study is to better predict the long-term success of MHP projects in rural areas of Nepal and help improve the project designs by the relevant stakeholders and assist the stakeholders in the certainty for future investment decisions.

\section{Sustainability assessment}

The concept of sustainability is difficult to put under one standard definition. Parris and Kates [19] pointed about more than 500 concepts to measure sustainability. This shows the diversity of definition and of ways to measure it. Back in 1987, the World Commission on Environment and Development focused on the development aspect of sustainability and established the well-known definition of sustainable development as "meeting the needs of the present without compromising the ability of future generations to meet their own needs." Sustainability is measured in different dimensions, which interact and depend on the used evaluation model. The most famous one is the Three Pillar Model with its economic, social, and environmental dimensions. In this study, the concept of sustainability is defined as the ability of a micro hydropower project in maintaining its operation for electricity supply while ensuring technical, economic, social, and environmental requirements.

The sustainability of any kind of off-grid rural electrification usually requires active local participation in the development and implementation of the electrification projects [20]. Mobilizing the necessary resources is often challenging. Rural electrification can hardly advance without the involvement of private finance and public coordination. At the same time, the commercial financial sector is reluctant to engage in rural off-grid investments. Increasing mobilization of local financial resources with active participation of the community in the rural areas is necessary but is hard to achieve among the poorest. Therefore, identifying innovative mechanisms to attract capital and increase financing is key to advancements in rural electrification and, ultimately, rural development [7]. The question always remains how to achieve this in rural regions. Besides the social benefits, decision makers tend to give more importance to the economic impact of access to electricity as an income-generating process. Such economic growth is obviously an important achievement of any rural electrification program [9]. Some experts [21], however, warned that the necessary conditions for such economic growth lie in the parallel or complementary development programs for the newly electrified communities. While electricity is indeed an important input to rural businesses, adequate local conditions such as organized rural markets and sufficient credits are necessary for such businesses to grow. Lack of such complementary development programs in these regions may hinder their economic growth [9]. An emphasis on simply providing electricity coverage in rural areas without adequate forethought to opportunities for business development and poverty reduction is not only undesirable but in the long run is unsustainable as valuable resources will be wasted. Also, energy in the context of failing schools, poor health facilities, and poor water supply will not lead to development [22]. To maximize the chances of sustaining operation of off-grid electrification projects over the long term, their design must ensure that all key factors along the value chain (e.g., consumers, service and technology providers, investors, and government) are taken into consideration [23]. A holistic planning approach is very important, which is also the approach of our present study.

There are many studies regarding sustainability assessment in general [24]. Several studies have assessed the indicators based on the sustainability of energy systems. Possible energy indicators for sustainability assessment are indicated by the International Atomic Energy Agency (IAEA) [25]. Indicator-based assessments have been carried out also elsewhere for off-grid electricity systems. Some of these studies are presented and reviewed below.

Ness et al. [26] analyzed different tools for the sustainability assessment and noted three main categories, one of them being indicators/indices. Other categories they identified were product-related assessment and integrated assessment tool. Authors found that the differences among the three tools lie mainly on the established guidelines available for the practitioners and frequency of their use. Obviously, for the environmental dimension (e.g., life cycle assessment), there are clear standards.

Lhendup [27] presented a case study in Bhutan where an indicator-based assessment method was applied to determine the best choice of a distributed generation system. After an estimation of the load demand within rural context, a subjective comparison was made by defining three sets of indicators: technical, regulatory, and socio-environmental indicators. The indicators were assigned weights according to their relevance. The options were compared to each other through a qualitative evaluation in which each of the alternatives achieved a score, which is the product of the performance of the option in relation to each parameter in the set, and multiplied by its assigned weight. The aggregation of the three sets is the final score of the alternative. The results generated a ranking of choices. The best options were then tested against another indicator.

A study by Ilskog presented a method for sustainability evaluation of rural electrification project based on the use of 39 indicators covering five dimensions of sustainability, namely, technical, economic, social/ethical, environmental, and institutional sustainability. The author argued that projects which were promoted on the basis of only certain dimensions of sustainability, such as environment, may fail as a result of weaknesses in other 
dimensions [28]. Another study by Ilskog and Kjellström exercised the use of the aforementioned method to assess seven rural electrification projects in Eastern and Southern Africa. It was found that when assessed against the different indicators covering the five different dimensions, the national utilities perform better from a social/ ethical perspective, whereas the private organizations and the community-based organizations manage their client relation issues in a more sustainable way [29].

Evans et al. [30] assessed different renewable energy technologies (photovoltaics, wind, hydro, geothermal) based on the sustainability indicators. Each technology was ranked from 1 to 4 according to the corresponding indicator, with 1 being the best (and 4 the least) technology for that indicator. However, each indicator was assumed to have equal importance to sustainable development. This could result in bias as some indicators might have more weight than others.

Some studies focused on different energy technologies for rural electrification and on specific country contexts, e.g., a study by Brent and Rogers [31], which carried out the sustainability assessment of renewable rural electrification (mini-hybrid off-grid) systems in South Africa. The study showed that, within a South African sustainable development framework, specific village renewable off-grid electrification system is not viable. Concerning sustainability assessment methods for hydropower, the "Hydropower Sustainability Assessment Protocol" published by the International Hydropower Association (IHA) [32] provides an appropriate approach. This protocol contains four separate assessment tools for the different project life cycle stages: early stage, preparation, implementation, and operation. The IHA method uses nine (early stage) to 23 (preparation) different assessment topics across four sustainability dimensions (or perspectives): economic, social, environmental, and technical. However, it is set up for larger-scale hydropower plants. Other assessment methodologies, although focusing on hydropower, are lacking suitability for our purpose. As our focus is MHP, a good example can be found in Upadhayay [33]; the author assessed the effectiveness of two Nepali MHPs with installed capacity of 50 and $44 \mathrm{~kW}$, respectively.

Bhattacharyya [34] compiled several analytical studies that use different indicators to predict the performance of a system in various aspects. While some used a singleindicator approach, e.g., levelized cost, to analyze the costeffectiveness of a system, others applied a set of indicators tackling various areas such as regulatory, technical, social, economic, and institutional frameworks. Some assigned weights and/or rankings to these indicators to calculate a final score. Such indicator-based approaches are criticized by the same author himself regarding the lack of integration of the non-included aspects in the single-indicator approach, leading to omissions that lead to miscalculations, and the subjectivity embedded in the choice of indicator weights and rankings in the multiple-indicator approach. On the other hand, he indicated that this issue can be undertaken by integrating a participatory process for weighting, ranking, or changing indicators, which in turn reduces the standardization of the method.

Hong and Abe [35] assessed the sustainability of renewable energy projects for off-grid rural electrification in an island in the Philippines. Most of the reviewed methods in the energy technology and rural electrification context are rather suitable to compare different technology alternatives than to assess sustainability of specific projects. Singh et al. [36] gave an overview of sustainability assessment methodologies, pointing out that the alignment of the assessment objective with the identified sustainability indicators becomes more difficult when measuring sustainability across various dimensions and aggregating the indicators to a single sustainability score. Furthermore, the authors argue that the indicator weighting system and the method used for aggregating the indicator scores play a predominant role in the formation of this single value.

The methodology of Morimoto [37] is designed for larger hydropower with only one economic indicator (electricity supply cost), one social indicator (number of resettled people), and one environmental index (biodiversity). In our view, this is insufficient to assess overall sustainability of such project as, in each dimension, there are many indicators affecting sustainability of a hydropower project.

Troldborg et al. [38] developed and applied a multicriteria analysis (MCA) for a national-scale sustainability assessment and ranking of 11 different renewable energy technologies in Scotland. The developed MCA considers nine criteria comprising three technical, three environmental, and three socio-economic criteria. The authors suggested that, when assessing the sustainability of different energy projects, it is important to address uncertainties associated with the input information which the MCA is based, in order to obtain more robust results and ensure better informed decision-making. Liu [39] proposed an assessment framework for renewable energy systems including the aggregation of several basic sustainability indicators to a general sustainability indicator or index. The framework can be used as guidance for the development of sustainability indicators for various renewable energy systems, but it does not provide a detailed assessment framework in an electrification context.

Santoyo-Castelazo and Azapagic [40] summarized 18 studies on sustainability assessment of electricity generation under the categories of aim and scope, time horizon, scenario analysis, sustainability indicators (numbers and life cycle approach), and integration of indices for a Mexican electricity system. They vary according to system boundaries (at the national, local, or technological level), time horizon (current, short, medium, and long term), the type 
and number of sustainability aspects and indicators considered (technical, environmental, economic, and social), methodologies for the assessment (e.g., life cycle assessment, life cycle costing), and methods for integrating sustainability considerations (e.g., subjective approach, multi-criteria decision analysis). The number of indicators varied from four [41] to 75 [42]. The authors used ten environmental, three economic, and four social sustainability indicators integrated within their sustainability assessment framework.

Maxim [43] ranked 13 electricity generation technologies using ten sustainability indicators in a weighted sum multi-attribute utility approach. Among these technologies, large hydro was the most sustainable followed by small hydro, and coal made the last in that list. Mainali et al. [44] introduced a rural energy sustainability index combining 13 techno-economic, environmental, and social indicators applied in six countries (China, India, South Africa, Sri Lanka, Bangladesh, and Ghana) between 1990 and 2010. The scale of this method is a national strategic level, thus different from the scale needed for the present study. The authors stated that it would provide better insight when applied to larger sets of countries.

Kumar and Katoch [45] presented a review of sustainability indicators for run of the river hydropower projects in India. They presented the hydropower sustainability indicators under social, environmental, and economic dimensions. Authors pointed out that decision makers need to choose the sustainability indicators and implement them as per sustainability need of the specific region and type of project. In another study, Kumar and Katoch [46] carried out a sustainability assessment of small hydropower plants in the western Indian Himalayan Region. They used the common perspectives of sustainability: environmental, social, and economic. Small hydropower plants have been identified as one of the main pressure points in the sustainable development of Himalayan regions of India and neighboring countries.

Lillo et al. [47] discussed five dimensions of sustainability: technical, economic, social/ethical, environmental, and organizational/institutional. An innovative management model was created to provide basic energy and sanitation services with six different technologies: MHP, individual photovoltaic systems, bio-digesters, improved cook stoves, Trombe walls, and solar water heaters. Results showed that the best dimension is organizational/ institutional, the second one is technical, the third and fourth are environmental and economic, respectively, with similar results, and finally the fifth is social/ethical. These dimensions have an average score of 0.97, 0.88, 0.71, 0.68, and 0.47 , respectively.

Palit and Bandyopadhyay [48] carried out a review on rural electricity access in South Asia. Despite a large number of rural electrification projects being financed internationally, there is limited literature on sustainability analysis of rural electrification programs. In their recent paper, Singh and Nachtnebel [49] presented some recommendations for hydropower development in Nepal. The authors used analytical hierarchy process (AHP) as the assessment method for finding the most appropriate scale of hydropower. They selected five criteria, technical, social, environmental, economic, and political, and 23 sub-criteria. These criteria were weighted differently. Based on responses obtained from survey, the highest weightage was given to economic (24.4\%) criteria, followed by political $(21.0 \%)$, technical (20.1\%), social $(18.9 \%)$, and environmental (15.5\%) criteria. It also concluded medium-scale hydropower as the most appropriate scale, followed closely by big hydropower schemes in ranking.

Based on these indicator-based analyses in the literatures, relevant indicators covering different sustainability dimensions were selected, weighted, and used for the sustainability assessment of an MHP project in a remote area of Nepal.

\section{Methods}

After reviewing the relevant available literatures and getting an overview on energy supply and demand situation in Nepal, our research focused on identifying suitable indicators and assessment methods for a sustainable operation of micro hydropower plants. A schematic diagram of the overall methodology used to carry out this study is shown in Fig. 1.

The methodology distributed the different indicators into four sustainability assessment dimensions: economic, social, environmental and technical. Each dimension was divided further into themes as shown in Fig. 2. The themes were further divided into indicators. The initial indicators were developed before the field visit to the MHP case study site in Nepal, and they were later modified with the participation of stakeholders. At first, they were discussed with the experts in a workshop in Kathmandu and afterwards they were refined and finalized on site during another workshop with all relevant stakeholders such as the local villagers, operators and the community manager. In order to feed data to the indicators, set of questionnaires for the target groups was developed and then data were collected from the community members, manager, operator and the technical / policy experts. The questionnaire was designed based on the selected indicators. After the field visit, previously developed indicators were revised and finalized to their current form. The scoring system was intensively discussed and agreed with the stakeholders on site.

The aim of the developed sustainable operation model is to determine an overall score to the sustainability 


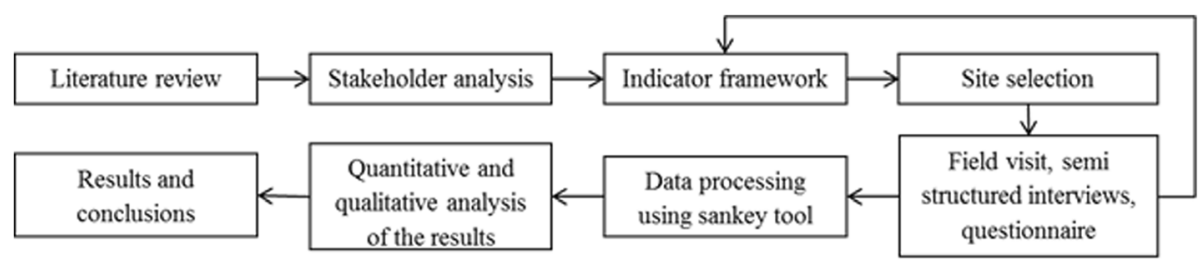

Fig. 1 Schematic diagram of the methodology used for the sustainability assessment

dimensions of the considered MHP. Therefore, the indicator system is equipped with a scoring index, which sets the conditions for a scoring of the respective indicator from 1 to 5 (with 5 being the best), as adopted from the scaling system recommended by the aforementioned IHA's Hydropower Sustainability Assessment Protocol report.

The model includes a weighting measure of the indicators within the themes as well as a weighting of the themes to the dimension score according to their importance. The indicators were weighted within each theme, and the themes again were weighted within the dimensions. For indicators that could not be scored, a score of zero was assigned. If this happens for one indicator theme, it was left as it is, but if there were two or more indicators in the theme, the weighting was adjusted, as what we call "actual weighting" (i.e., if there are two indicators in a theme, each worth $50 \%$ and one is zero, and the other non-zero one has an "actual weighting" of $100 \%$ ). The scoring tool solves this issue for an arbitrary indicator $\mathrm{xj}$ of a theme with $n$ indicators, $\mathrm{j} \in\{1, \ldots, n\}$, as given by:
Actual weighting $(x \mathbf{j})=\operatorname{IF}($ Score $(x \mathbf{j})=0), 0$;

$$
\text { ELSE } \frac{\text { Weighting }(x j)}{1-\sum_{i=1}^{m} x i}, x i, i=1, \ldots, m,
$$

weight of the indicators with score 0

This means the actual weighting of an indicator within a theme is the pre-set weighting divided by the sum of indicator weightings within the theme which are not zero. If none is zero, the actual weighting equals to weighting. The same method applies for the actual weighting of themes within a dimension (in that case, $x j$ is a theme).

\section{Case study site}

The visited MHP is located in Mahadevsthan, Dhading District of Nepal (Fig. 3). It lies in a rural and remote hilly region, around 1-h drive from the next bigger village, Malekhu, located at the main road leading to the capital Kathmandu. The MHP site was chosen for this

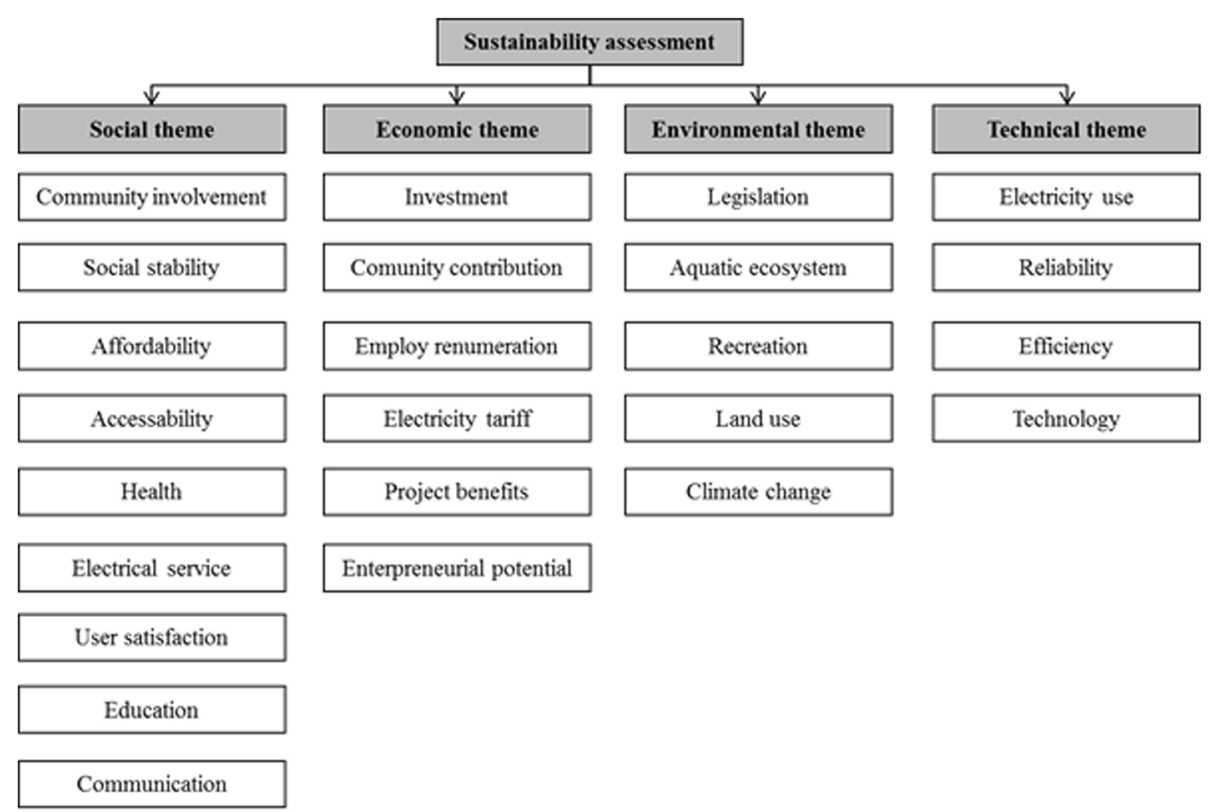

Fig. 2 The list of themes under each sustainability dimension 


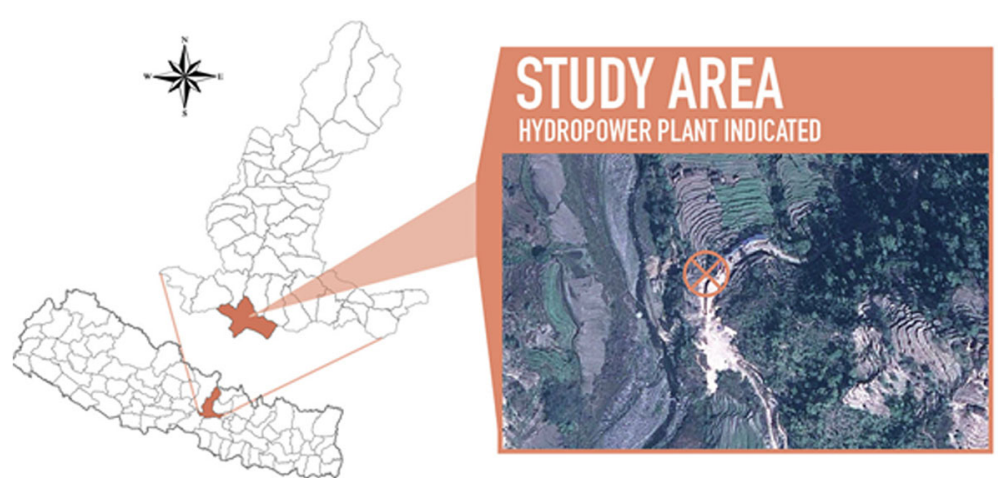

Fig. 3 Study area location of the MHP site in Mahadevsthan, Dhading District, Nepal [51]

study because it offers the best-case scenario for project development, based on its typical mountainous terrain and the availability of water resources for the establishment of a micro hydro plant.

The plant, which is owned by the community itself, has an installed capacity of $26 \mathrm{~kW}$. It has a gross head of $25 \mathrm{~m}$ and a water flow rate of $212 \mathrm{l} / \mathrm{s}$. An additional $83 \mathrm{l} / \mathrm{s}$ flow is allocated for irrigation purposes. It uses a synchronous generator and a cross-flow turbine. According to the detailed feasibility study carried out in 2006 before the plant installation, the project costs were estimated at 4.4 million NRs (115 NRs equals about 1 Euro as of June 2016) with an Alternative Energy Promotion Centre (AEPC)/Rural Energy Development Programme (REDP) subsidy of 1.82 million NRs $(70,000 \mathrm{NRs} / \mathrm{kW})$. The financial mix of the studied MHP is shown in Table 1.

This research is based on quantitative and qualitative data collected through interviews. Using the questionnaires elaborated beforehand, relevant data about the development of the Mahadevsthan MHP since its feasibility study in 2006 was gathered to feed to our indicator system. In total, 15 community households, the chairman of the Management Committee, the operator, and three AEPC experts (consisting of two local and one national) were consulted. Although the selected household sample size is relatively small (e.g., according to the method by

Table 1 Financial mix of studied MHP (modified from DECEEC [52])

\begin{tabular}{llll}
\hline Sources & Amount (NRs) & Share (\%) & Remarks \\
\hline Subsidy & $1,820,000$ & 41.23 & AEPC/REDP subsidy \\
DDC investment & 220,736 & 5.00 & Estimated 5\% of TPC \\
VDC investment & 220,736 & 5.00 & Estimated 5\% of TPC \\
Bank loan & 960,148 & 21.75 & \\
Community equity & 928,091 & 21.02 & Local cost \\
Cash collection & 265,000 & 6.00 & NRs 1000/HH \\
Total source of finance & $4,414,711$ & 100.00 & \\
Unit cost (NRs/W) & 170 & & \\
\hline
\end{tabular}

Yamane [50], care had been taken in the selection of the household groups. The groups were selected based on their relative income levels (low-, middle-, and highincome levels) as to ensure representative sampling according to the income level.

Besides the interviews with locals, we also had two workshops with the villagers and with additional experts in Kathmandu. In assessing the economic benefit of the MHP project, we reviewed the economic activities affected by the MHP in the area. From the experience of our field visit, we found that crops such as paddy rice, maize, and seasonal/non-seasonal vegetables are prevalent farming choices. A lift irrigation system installed in 2013 with $2.3 \mathrm{~kW}$ submersible pump transports water at $1 \mathrm{l} / \mathrm{s}$, overcoming a height difference of $140 \mathrm{~m}$, supplying irrigation water to a 75-ha land. The system is still in its testing phase, and a second lift irrigation system is being constructed. This irrigation system offers an increased opportunity to sell crops to the Malekhu market. Moreover, besides key benefits such as light provision and refrigeration, the following facilities powered by the MHP electricity also provide benefits to the village: two agroproceeding units (milling), several poultries, two primary schools, a carpentry, a photocopy shop, a tailoring shop, a secondary school, a village development committee (VDC) office, a health center, an electronic repair center, and a computer lab (with seven computers).

The number of served households rose from 265 at the start of the MHP operation in 2008 to currently $307 \mathrm{~kW}$. It can be said that the provision of electricity to the village has been received very positively by the community members. Electricity is used mainly for provision of lighting, cooking, water heating, refrigeration, tailoring, watching $\mathrm{TV}$, listening to the radio, or charging mobile phones. About $80 \%$ of the interviewees have at least one mobile phone in their household (HH), 40\% have a TV, 26.7\% have a computer, and 20\% have an Internet access. On average, the HHs use around five appliances at the same time, such as rice cooker, TV, mobile charger, fridge, or 
light bulbs. Quality of life has increased with the use of those electrical appliances or through more availability of time for work, study, or leisure activities (e.g., watching $\mathrm{TV}$ ) due to average saving of $4 \mathrm{~h} /$ day that is no longer dedicated for firewood collection. New poultry farms are opened, and the restaurant owner now receives more visitors due to extended working hours and available light. The rice mill (one of the above listed agro-proceeding units) saves the time to go to market in Malekhu. Children have on average $2 \mathrm{~h}$ more time available for their studies in the evening. Furthermore, the replacement of firewood and kerosene by electricity has lowered the risk of respiratory diseases and fire incidents. The people interviewed confirmed $2.5 \mathrm{l} / \mathrm{m}-\mathrm{HH}$ kerosene consumption before MHP establishment, as given in the feasibility study report. The same is valid for the feasibility study's aim to $0.5 \mathrm{l}$ after MHP electricity; many are not using kerosene any more in everyday life. However, in case of electricity shortage, kerosene lamps (53.3\% of survey sample) and torchlight (40\%) are the most used appliances for lighting purposes.

Regarding the environmental dimension, fish reduction in the river was observed, but not necessarily attributed to MHP operation. Except for some trees that were cut for the extension of the distribution line, no change in natural surroundings due to the MHP was noticed. In contrast, its establishment has brought benefits to farmers by means of operated lift irrigation system mentioned above. As many as $26.6 \%$ of the interviewees are taking part in the pilot irrigation project; another $20 \%$ is planning to use it since it provides better income opportunities and easiness of use. In general, the electricity service is considered reliable and fair for the population. The majority considers that the fixed electricity tariff of 80 NRs (raised from 60 NRs in the beginning) until a monthly consumption of $20 \mathrm{kWh}$ and the variable rate of $7 \mathrm{NRs} / \mathrm{kWh}$ above $20 \mathrm{kWh}$ are reasonable. People who migrated to the village after MHP establishment and consequently had not participated in the construction work have to pay $7000 \mathrm{NRs}$ in order to use the electricity service. Most of the villagers were satisfied with the management performance, except the carpentry owner, who complained about his unfulfilled wish of a three-phase supply despite several requests. Regarding the operational reliability, $20 \%$ of the surveyed samples complained about the frequent interruptions during the monsoon season. Community meeting usually takes place once a month, in which such complaints can be communicated to the management committee. Other complaints concerned with the problem of a missing substitute for the operator (especially during long public holidays), the replacement of a wooden pole with a steel pole, and the saturated capacity of the plant (demanding higher supply). There is a quite high participation rate in community meetings, with an estimated 50:50 ratio between women and men.

The survey on the entrepreneurial development of the villagers gave ideas of additional MHP electricity-powered economical/industrial activities like a mustard mill, offseason vegetable farming (with irrigation), dairy farming (storing of milk), welding, tailoring, knitting, and handicraft for trade. The MHP operator confirmed the running time of the plant of $22 \mathrm{~h}$ /day (up to $24 \mathrm{~h}$ /day during rainy season); he turns it off between 11:00 am and 1:00 pm. The energy yield of the MHP is shown in Fig. 4.

\section{Results}

With case study indicator scores defined and weightages included in the model, the theme and dimensional scores

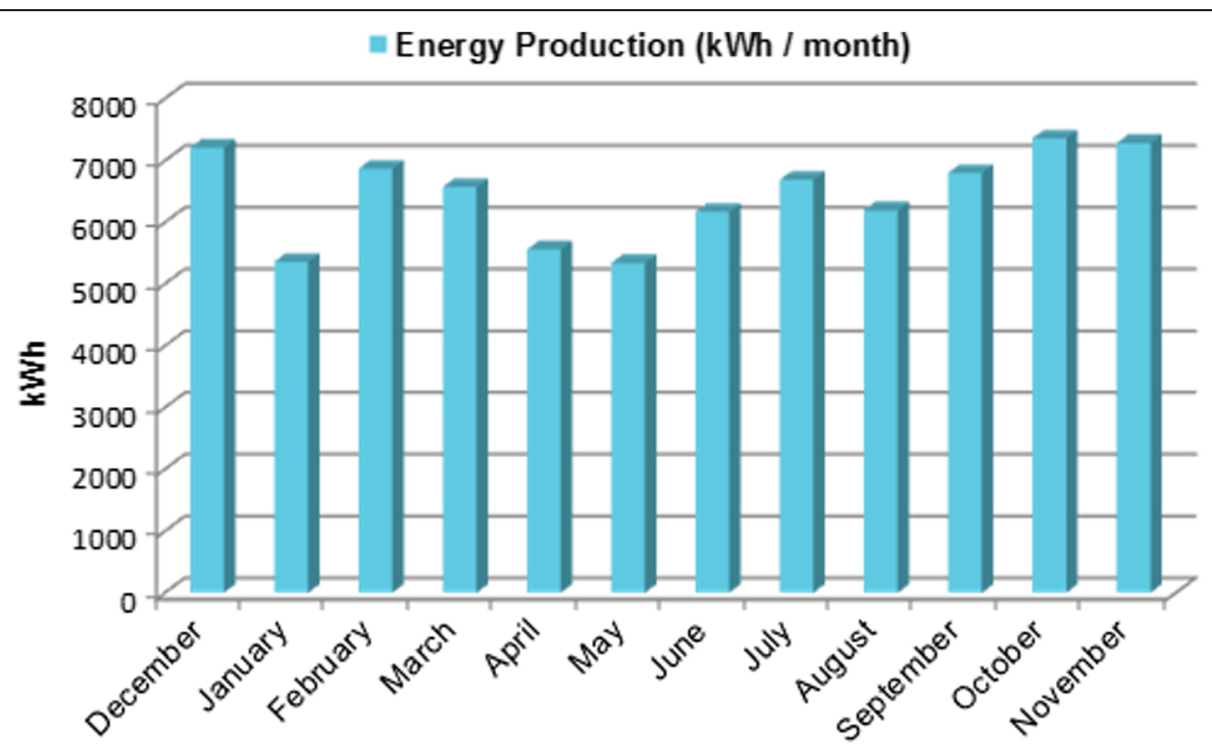

Fig. 4 Electricity production per month 
were calculated and the results are presented in Tables 2, 3,4 , and 5 .

As seen in Tables 2, 3, 4, and 5, social dimension shows the best performance with a score of 4.17 for the studied MHP, followed by environmental (3.94), economic (3.74), and technical dimensions (3.04).

\section{Discussions}

As we previously implied in the "Methods" section, different dimensions comprising sustainability of an MHP project must be weighted according to their importance. Based on our data collection, interviews, and observation of the impact of the MHP project pre- and postimplementation, we assigned the weightages to economic and social dimensions equally at $30 \%$, technical at $25 \%$, and environmental at $15 \%$. For other plants and sites in the rural areas of Nepal, this weight distribution might be slightly different in number, but we estimate that the priority could be the same, i.e., economic and social dimensions will play vital roles. Using those weightages, a final score of 3.73 was obtained for the studied MHP. However, we recommend not to aggregate the dimensional scores into one single score as more site-specific data from different sites are needed to assign more accurate weight distribution for each sustainability dimension in the different sites.

Although the "Notes on Scoring" column detailed in the tables presented an individual message behind each scoring, we estimate that the types of the indicators in other remote areas of Nepal will be similar. However, to minimize biases, customized assessment frameworks could be developed. The key to the success of such assessment is mainly in involving all relevant stakeholders in providing the inputs. The engagement of a wide variety of stakeholders is crucial in recognizing all relevant indicators. In addition to that, as these days technology is rapidly changing and the intense effects of globalization can be seen on rural communities (for example due to the use of smartphones), conditions for defining sustainability in different dimensions could also change with time, depending on the current as well as future values accepted in the rural communities.

A closer look on the assessment Tables 2, 3, 4, and 5) could also provide insight into designing a better MHP, in terms of technical, social, economic, and environmental aspects, so that future MHPs have better sustainability in all these dimensions, which could be indicated by the increase in the sustainability score. Recommendations on how to improve the score is given below in a site-specific context.

In terms of technical sustainability, we assigned low scores for maintenance program quality, capacity factor, and program of asset upgrades, with scores of 2, 2, and 1, respectively. MHPs are normally systems with a low level of automation, yet only one employee often controls the operation. The technical performance of the energy supply is, therefore, dependent on the actions of the operator in charge. From the end users' point of view, this caused supply interruptions for reasons outside their control (generation, operations, maintenance, and distribution). It has been noticed that having a trained substitute that can manage and operate the MHP in absence of the main operator is key for a reliable operation. Often, maintenance or "replacing parts before they break" is also ignored in small-scale projects. This is often due to a small budget or due to a lack of experience. However, a well-made maintenance plan, combined with the strict application of such, increases the lifetime of machinery and therefore reduces costs for machinery replacement. A maintenance

Table 2 Scores for the technical sustainability dimension

\begin{tabular}{|c|c|c|c|c|c|c|}
\hline Themes & Dimensional weighting (\%) & Code & Indicators & Score & Notes on scoring & Theme score \\
\hline \multirow[t]{4}{*}{ Usage } & \multirow[t]{4}{*}{30} & $\mathrm{~T} 1$ & $\begin{array}{l}\text { Serviceability performance of } \\
\text { energy supply }\end{array}$ & 4 & $\begin{array}{l}\text { Community is informed about the switching } \\
\text { pattern; no continuous supply }\end{array}$ & \multirow[t]{4}{*}{4.00} \\
\hline & & $\mathrm{T} 2$ & Load factor & 4 & Load factor is high as ballast load is attached & \\
\hline & & T3 & $\begin{array}{l}\text { Plant factor (downtime } \\
\text { (days/year)) }\end{array}$ & 0 & Unable to score & \\
\hline & & T4 & Design of the grid & 4 & Systematic approach & \\
\hline \multirow[t]{2}{*}{ Reliability } & \multirow[t]{2}{*}{15} & T5 & Maintenance program quality & 2 & No clear schedule communicated & \multirow[t]{2}{*}{3.20} \\
\hline & & T6 & Quality of power & 4 & Fluctuations are generally not noticeable & \\
\hline \multirow[t]{3}{*}{ Efficiency } & \multirow[t]{3}{*}{30} & $\mathrm{T7}$ & Capacity factor & 2 & Around $40 \%$ & \multirow[t]{3}{*}{2.25} \\
\hline & & T8 & Machinery efficiency & 0 & Unable to score & \\
\hline & & T9 & $\begin{array}{l}\text { Grid efficiency and expansion } \\
\text { possibility }\end{array}$ & 3 & Moderate costs & \\
\hline \multirow[t]{3}{*}{ Technology } & \multirow[t]{3}{*}{25} & $\mathrm{~T} 10$ & Program of asset upgrades & 1 & No plan & \multirow[t]{3}{*}{2.80} \\
\hline & & $\mathrm{T} 11$ & Possibility for upgrading/expansion & 3 & Turbine with higher efficiency can be installed & \\
\hline & & $\mathrm{T} 12$ & $\begin{array}{l}\text { Replication of program in nearby } \\
\text { villages }\end{array}$ & 5 & $\begin{array}{l}\text { Can be built at multiple locations along the } \\
\text { same river }\end{array}$ & \\
\hline \multicolumn{3}{|c|}{ Aggregated score-technical dimension } & & & & 3.06 \\
\hline
\end{tabular}


Table 3 Scores for the economic sustainability dimension

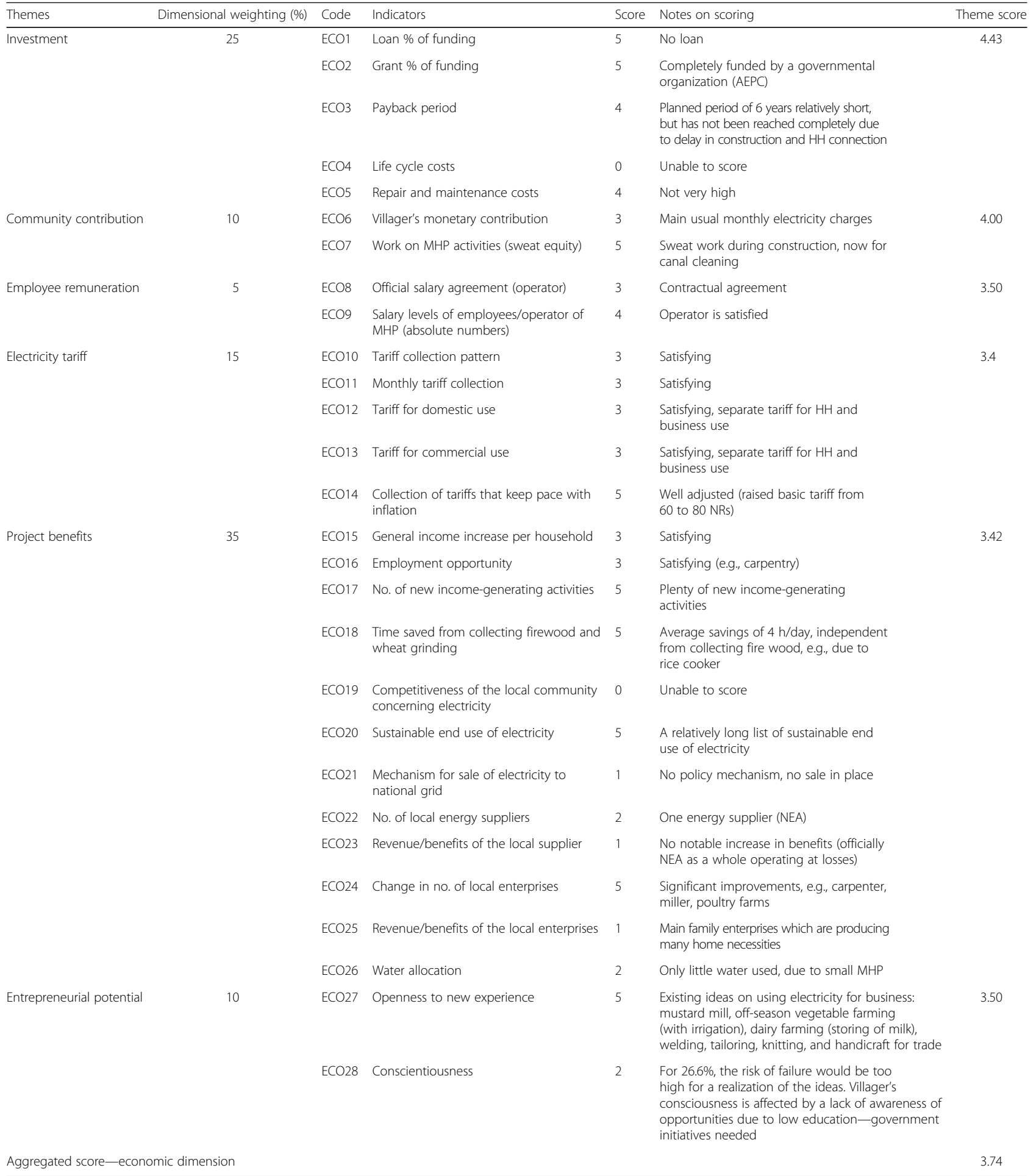

schedule for the plant should be provided by the contractors and compiled based on the manufacturers' handbook of each item of machinery. Contractors should provide guidelines, not only consisting of standard guidelines covering operational aspect but also of troubleshooting and maintenance, which include the availability of critical rotating parts. As has been shown in the "Conclusions" section, the villagers rely a lot their daily activities on the MHP electricity supply; therefore, supply interruption should be avoided. 
Table 4 Scores for the environmental sustainability dimension

\begin{tabular}{|c|c|c|c|c|c|c|}
\hline Themes & $\begin{array}{l}\text { Dimensional } \\
\text { weighting (\%) }\end{array}$ & Code & Indicators & Score & Notes on scoring & Theme score \\
\hline Law & 15 & ENV1 & $\begin{array}{l}\text { Compliance with } \\
\text { legislation }\end{array}$ & 4 & $\begin{array}{l}\text { Working policies are largely implemented } \\
\text { (integration with irrigation, education, health, } \\
\text { small-scale industry; use of locally available } \\
\text { skill where possible; technical assistance } \\
\text { from DDC), minor points are missing (no } \\
\text { integration with drinking water, late decision } \\
\text { for subsidies with Subsidy Policy 2011/12) }\end{array}$ & 4.00 \\
\hline \multirow[t]{3}{*}{ Aquatic ecosystem } & 15 & ENV2 & $\begin{array}{l}\text { Level of interference } \\
\text { with fish population } \\
\text { and other aquatic } \\
\text { species }\end{array}$ & 4 & No major impact on fish population & 4.00 \\
\hline & & ENV3 & $\begin{array}{l}\text { Interruption of river } \\
\text { continuum, inverse } \\
\text { to quality of fish } \\
\text { bypass system }\end{array}$ & 0 & Unable to score & \\
\hline & & ENV4 & $\begin{array}{l}\text { Share of water taken } \\
\text { from the river }\end{array}$ & 4 & $\begin{array}{l}\text { Share of water taken from river is adequate } \\
\text { and could even be exploited more, provided } \\
\text { that share complies with regulations }\end{array}$ & \\
\hline \multirow[t]{2}{*}{ Recreation } & 15 & ENV5 & Landscape & 3 & $\begin{array}{l}\text { Some visible impacts on landscape beauty } \\
\text { due to electricity poles and transmission lines }\end{array}$ & 3.00 \\
\hline & & ENV6 & $\begin{array}{l}\text { Noise emissions } \\
\text { from powerhouse }\end{array}$ & 3 & $\begin{array}{l}\text { No disturbance for villagers except for operator, } \\
\text { who sleeps in the power house }\end{array}$ & \\
\hline \multirow[t]{2}{*}{ Land } & 15 & ENV7 & Erosion & 4 & $\begin{array}{l}\text { Vulnerability to erosion is low, canal made of } \\
\text { concrete }\end{array}$ & 4.60 \\
\hline & & ENV8 & Sedimentation & 5 & $\begin{array}{l}\text { Desilting tank and regular cleaning/maintenance } \\
\text { as model recommendation }\end{array}$ & \\
\hline \multirow[t]{3}{*}{ Climate change } & 40 & ENV9 & $\begin{array}{l}\text { Fossil fuels avoided } \\
\text { (GHG emissions) }\end{array}$ & 4 & $\begin{array}{l}\text { Feasibility study goals are reached (kerosene } \\
\text { demand reduced to } 0.5 \mathrm{l} / \mathrm{m}-\mathrm{HH} \text { ) and could be } \\
\text { surpassed slightly }\end{array}$ & 4.00 \\
\hline & & ENV10 & Rate of deforestation & 4 & $\begin{array}{l}\text { Firewood consumption is reduced remarkably } \\
\text { by MHP electricity }\end{array}$ & \\
\hline & & ENV11 & Flood protection & 4 & $\begin{array}{l}\text { Curbstones are placed in vulnerable section } \\
\text { of a headrace canal. Inundation area at intake } \\
\text { seems adequate, minor criticism-dispersed } \\
\text { area; it could be better structured }\end{array}$ & \\
\hline \multicolumn{5}{|c|}{ Aggregated score-environmental dimension } & & 3.94 \\
\hline
\end{tabular}

Also, it is necessary to provide some trainings and awareness campaigns to the villagers on entrepreneurial activities by using the electricity in off-peak hours. An important use of electricity is to improve the education by using new technologies at the local education institution and by increasing the learning hours for children in the evening. Access to new technologies for households is an intrinsic benefit that electricity provided an improved access to communication and information technologies.

In terms of economic sustainability, low scores were assigned to mechanism for sale of electricity to national grid, number of local energy suppliers, revenue/benefits to the local suppliers, revenue/benefits to the local enterprises, water allocation, and conscientiousness. The scores of these indicators are either 1 or 2. Except for water allocation, all others require an institutional and regulatory framework, such as government initiatives, and need a further/separate study.
Ownership is a valuable indicator to assess involvement and participation of the community in the MHP project. If local villagers embrace the project as their own, they will be more aware and willing to work together to achieve a common goal effectively. It is important to try to obtain the most material and equipment possible from local or regional markets in order to promote other economic activities around the MHP. Affordability of the electricity via MHP is of high importance in order to allow everyone in the community to have access to it. To assess the price in a neutral basis, the ratio of monthly expenditure for electricity as part of the total budget of a household was used. Assessing the numbers of complaints from villagers allows evaluating how the MHP is performing.

\section{Conclusions}

There is no doubt that the end users in the Nepalese villages such as Mahadevsthan in Dhading District are 


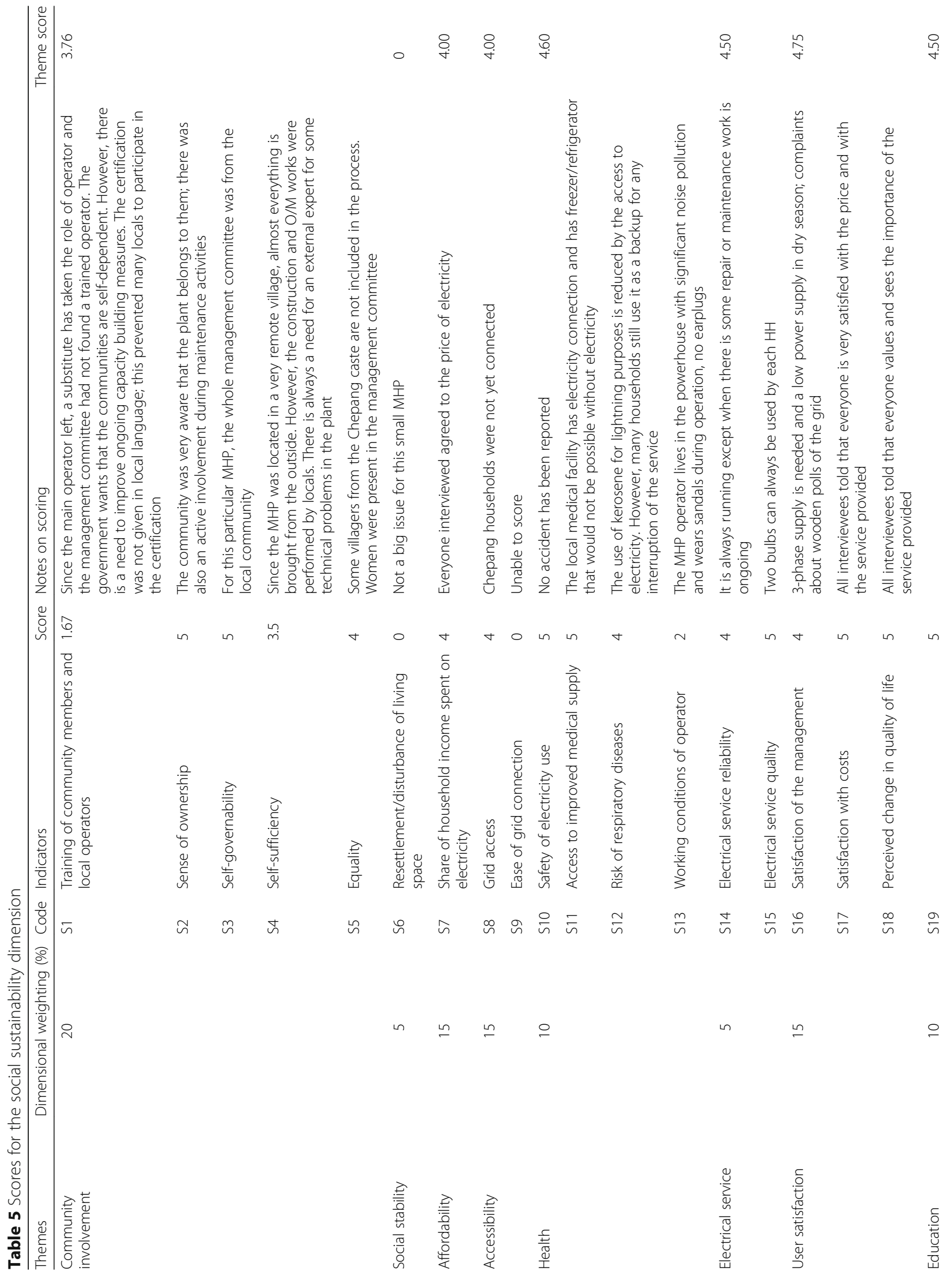




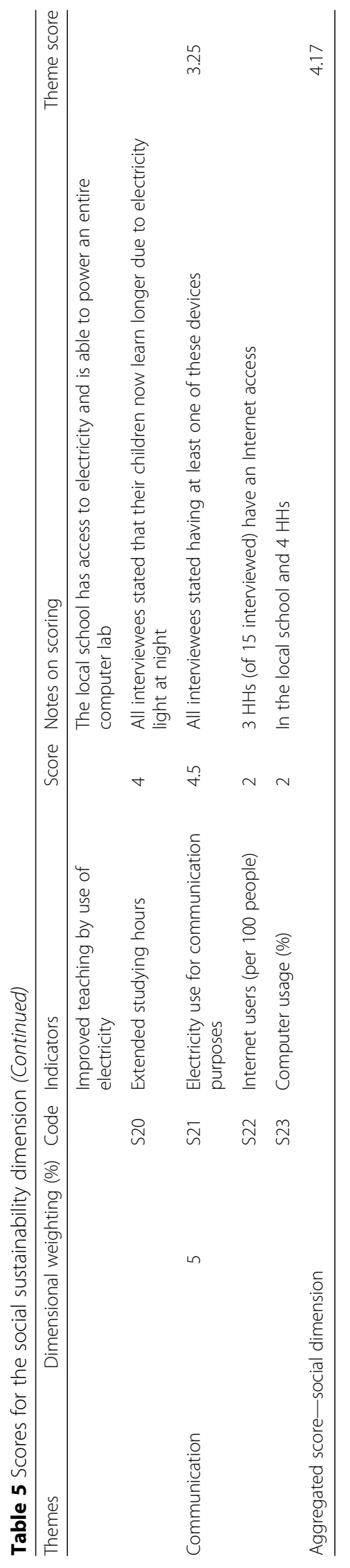


enjoying the common benefits of electrification similar to elsewhere: electricity for economic activity (in agriculture, in household-scale businesses, etc.), for schools, for household lightings, for communication and entertainment devices, and for other appliances. A big portion of the end user is highly satisfied with the supply of MHP electricity. Overall, the rural electrification is important in the country's numerous villages, as it can contribute to the local socio-economic development. However, this can be achieved effectively only when the sustainability of rural electrification projects is ensured. In this study, an attempt has been made to develop a sustainability assessment model and the necessary data have been collected for a case study site. The model proposed a sustainability assessment tool for the operational phase of micro hydropower plants, serving as a base for comparison among different projects. Although the sustainability dimensions used in the model are similar to those commonly used in literatures, our indicators are adapted to the country's local site context. We identified 54 assessment indicators across economic, social, environmental, and technical sustainability dimensions. A scoring system for the indicators was applied. Weighting across different dimensions were developed according to their importance. The analysis shows that this model could be applied to measure the sustainability level of such projects qualitatively and quantitatively, allowing easiness for future comparison with similar MHP projects and allowing easiness of identification on indicators that need improvement. With slight modification to the indicators and dataset, it could be transferred to measure the sustainability of other rural energy supply systems, especially solar home systems that are most widely used in Nepal. A ranking of rural electrification systems could help the policy makers to reshape their regulatory and fiscal policies in the field of rural energy supply.

However, some consideration should be taken before this model is used for the sustainability ranking of projects. Firstly, it should be noted that the developed indicators are applicable only to small-scale projects such as MHP. Secondly, while the single-score method assigns a simple single overall score by a weighted aggregation of the dimensions, we recommend to use the dimensional score method which skips this aggregation step and leaves the dimension scores as they are, as it provides better head-to-head insight for the same dimensions and reduces potential errors caused by inaccuracy in assigning appropriate weights for different dimensions. A successful use of this model in other projects could be achieved by ensuring engagement of all relevant stakeholders in designing a customized assessment framework which allows identification and involvement of site-specific sustainability indicators, as is demonstrated in this work.
To increase the sustainability of the MHP project, it is important to identify highly significant indicators and to give a stronger consideration of those indicators in the dimensional scores. The idea behind is that if those indicators perform badly, the dimensional score cannot surpass a certain benchmark level. It is also important to transfer the lesson learned from one site to another by focusing on indicators that are still scoring low in an existing project. In this case, operators are those who keep the system running, yet they are at the bottom of the hierarchy. Operational and management system should be handled professionally, capacity buildings and awareness should be improved, and checks and balances system should be developed. With current operation and management style, it is difficult to ensure the sustainability of the project. Moreover, economic dimension needs to be expanded by indicators concerning the whole energy market structure and the certain economic importance of the case study site/country. Further studies could focus on the extension of this model by applying our model to other MHP as well as non-hydro rural electrification projects. Nevertheless, this model serves as a starting point for sustainability assessment of micro hydropower projects in Nepal. It creates the basis for comparison of projects, and the model results could be used as a base for decisionmaking in the sector of development cooperation and, in particular, sustainability of rural energy supply systems.

\section{Abbreviations}

AEPC: Alternative Energy Promotion Centre; DDC: District Development Committee; ECO: Economic; ENV: Environmental; HH: Household;

IAEA: International Atomic Energy Agency; IHA: International Hydropower Association; MHP: Micro hydropower plant; NEA: Nepal Electricity Authority; NRs: Nepali rupees; REDP: Rural Energy Development Programme; S: Social; T: Technical; TPC: Total project cost; TV: Television; VDC: Village development committee

\section{Acknowledgements}

Thanks are due to many individuals who supported the data collection process and on-site field survey, especially Prof. Dr. Tri Ratna Bajracharya and Dr. Shree Raj Shakya from Centre for Energy Studies, Institute of Engineering, Tribhuvan University, Nepal. We also thank Ms. Christin Wolf, Mr. Christian Maywurm, Mr. David Arndt, Mr. Julio Santos, Mr. Raul Ríos, and Ms. Sarah Tschanun from TH Köln (University of Applied Sciences), Germany, for their support in data collection.

\section{Funding}

The travel costs for the field trip were financed by DAAD. There was no other research fund available, except the author's regular salary at the university.

\section{Authors' contributions}

RB developed the concept and research design. He visited the field for data collection. LGS contributed to the analysis and writing. WK contributed to the literature review and analysis. Writing was done together, RB about 50\%, LGS about 30\%, and WK about 20\%. LGS contributed significantly for the second revision of the manuscript. All authors read and approved the final manuscript.

Competing interests

The authors declare that they have no competing interests. 


\section{Publisher's Note}

Springer Nature remains neutral with regard to jurisdictional claims in published maps and institutional affiliations.

\section{Author details Germany. \\ Received: 7 March 2017 Accepted: 3 January 2018 Published online: 09 February 2018}

'Institute for Technology and Resources Management in the Tropics and Subtropics, TH Köln (University of Applied Sciences), Betzdorfer Strasse 2, 50679 Cologne, Germany. ${ }^{2}$ Institute for Electrical Power Engineering, TH Köln (University of Applied Sciences), Betzdorfer Strasse 2, 50679 Cologne,

\section{References}

1. IEA (2017) Energy Access Outlook 2017: from poverty to prosperity. IEA (International Energy Agency), Paris, France

2. IEA (2014) International Energy Agency—statistics search. IEA (International Energy Agency), Paris, France

3. Katuwal H, Bohara AK (2009) Biogas: a promising renewable technology and its impact on rural households in Nepal. Renew Sust Energ Rev 13(9):2668-2674

4. Lee C-C, Chang C-P (2008) Energy consumption and economic growth in Asian economies: a more comprehensive analysis using panel data. Resour Energy Econ 30(1):50-65

5. Nexant, Subsidizing rural electrification in South Asia: an introductory guide. New Delhi: USAID SARI Energy Programme; 2004.

6. UN, United Nations Open Working Group proposal for Sustainable Development Goals. New York: United Nations; 2014.

7. Mainali B, Silveira S (2011) Financing off-grid rural electrification: country case Nepal. Energy 36(4):2194-2201

8. Kaygusuz K (2011) Energy services and energy poverty for sustainable rural development. Renew Sust Energ Rev 15(2):936-947

9. IEA (2010) Comparative study on rural electrification policies in emerging economies. International Energy Agency (IEA), Paris, France

10. Zomers A (2003) The challenge of rural electrification. Energy Sustainable Dev 7(1):69-76

11. IEA-PVPS (2003) PV for rural electrification in developing countries - programme design, planning and implementation. IEA PVPS REPORT T9-05, Paris, France

12. HIDC (2014) Nepal hydropower overview. HIDC (Hydroelectricity Investment and Development Company Ltd.), Kathmandu, Nepal

13. Adhikari D (2006) Hydropower development in Nepal. Nepal Rastra Bank Econ Rev 18:70-94

14. NEA (2014) Annual report of Nepal Electricity Authority. NEA (Nepal Electricity Authority), Kathmandu, Nepal

15. World Bank (2014) The World Bank Indicators. World Bank, Washington DC, USA

16. Knoema. Nepal_-population growth rate. 2017 [cited 25 Nov 2017]; Available from: https://knoema.com/atlas/Nepal/Population-growth-rate

17. Parajuli R et al (2014) Energy consumption projection of Nepal: an econometric approach. Renew Energy 63:432-444

18. AEPC (2014) A year in review_July 2012_July 2013. Government of Nepal, Kathmandu, Nepal

19. Parris TM, Kates RW (2003) Characterizing and measuring sustainable development. Annu Rev Environ Resour 28(1):559-586

20. Pigaht M, van der Plas RJ (2009) Innovative private micro-hydro power development in Rwanda. Energy Policy 37(11):4753-4760

21. Barnes DF (2007) The challenge of rural electrification: strategies for developing countries. Resources for the Future. Washington. RFF Press, Washington DC

22. Harsdorff M, Peters J (2010) In: Schmidt CM (ed) On-grid rural electrification in Benin-a socio-economic baseline study on a GTZ project. RWI (Rheinisch-Westfälisches Institut für Wirtschaftsforschung), Essen, Germany

23. World-Bank (2008) Designing sustainable off-grid rural electrification projects: principles and practices. The World Bank Group, Washington DC, USA

24. Maywurm C (2016) Sustainability assessment of micro hydropower projects in Bolivia, in ITT. TH Köln (University of Applied Sciences), Cologne, Germany

25. IAEA (2005) Energy indicators for sustainable development: guidelines and methodologies. IAEA (International Atomic Energy Agency), Vienna, Austria

26. Ness B et al (2007) Categorising tools for sustainability assessment. Ecol Econ 60(3):498-508
27. Lhendup T (2008) Rural electrification in Bhutan and a methodology for evaluation of distributed generation system as an alternative option for rural electrification. Energy Sustainable Dev 12(3):13-24

28. Ilskog E (2008) Indicators for assessment of rural electrification —an approach for the comparison of apples and pears. Energy Policy 36(7):2665-2673

29. Ilskog E, Kjellström B (2008) And then they lived sustainably ever after? - assessment of rural electrification cases by means of indicators. Energy Policy 36(7):2674-2684

30. Evans A, Strezov V, Evans TJ (2009) Assessment of sustainability indicators for renewable energy technologies. Renew Sust Energ Rev 13(5):1082-1088

31. Brent AC, Rogers DE (2010) Renewable rural electrification: sustainability assessment of mini-hybrid off-grid technological systems in the African context. Renew Energy 35(1):257-265

32. IHA (2011) Hydropower sustainability assessment protocol. IHA (International Hydropower Association), London, UK

33. Upadhayay S (2009) Evaluating the effectiveness of micro-hydropower projects in Nepal. San José State University, San José, United States

34. Bhattacharyya SC (2012) Review of alternative methodologies for analysing off-grid electricity supply. Renew Sust Energ Rev 16(1):677-694

35. Hong GW, Abe N (2012) Sustainability assessment of renewable energy projects for off-grid rural electrification: the Pangan-an Island case in the Philippines. Renew Sust Energ Rev 16(1):54-64

36. Singh RK et al (2012) An overview of sustainability assessment methodologies. Ecol Indic 15(1):281-299

37. Morimoto R (2013) Incorporating socio-environmental considerations into project assessment models using multi-criteria analysis: a case study of Sri Lankan hydropower projects. Energy Policy 59:643-653

38. Troldborg M, Heslop S, Hough RL (2014) Assessing the sustainability of renewable energy technologies using multi-criteria analysis: suitability of approach for national-scale assessments and associated uncertainties. Renew Sust Energ Rev 39:1173-1184

39. Liu G (2014) Development of a general sustainability indicator for renewable energy systems: a review. Renew Sust Energ Rev 31:611-621

40. Santoyo-Castelazo E, Azapagic A (2014) Sustainability assessment of energy systems: integrating environmental, economic and social aspects. J Clean Prod 80:119-138

41. Heinrich $\mathrm{G}$ et al (2007) Ranking and selection of power expansion alternatives for multiple objectives under uncertainty. Energy 32(12):2350-2369

42. Roth $\mathrm{S}$ et al (2009) Sustainability of electricity supply technology portfolio. Ann Nucl Energy 36(3):409-416

43. Maxim A (2014) Sustainability assessment of electricity generation technologies using weighted multi-criteria decision analysis. Energy Policy 65:284-297

44. Mainali B et al (2014) Assessing rural energy sustainability in developing countries. Energy Sustainable Dev 19:15-28

45. Kumar D, Katoch SS (2014) Sustainability indicators for run of the river (RoR) hydropower projects in hydro rich regions of India. Renew Sust Energ Rev 35:101-108

46. Kumar D, Katoch SS (2015) Sustainability suspense of small hydropower projects: a study from western Himalayan region of India. Renew Energy 76:220-233

47. Lillo P et al (2015) A new integral management model and evaluation method to enhance sustainability of renewable energy projects for energy and sanitation services. Energy Sustainable Dev 29:1-12

48. Palit D, Bandyopadhyay KR (2016) Rural electricity access in South Asia: is grid extension the remedy? A critical review. Renew Sust Energ Rev 60:1505-1515

49. Singh RP, Nachtnebel HP (2016) Analytical hierarchy process (AHP) application for reinforcement of hydropower strategy in Nepal. Renew Sust Energ Rev 55:43-58

50. Yamane T (1967) Statistics: an introductory analysis, 2nd edn. Harper and Row, New York

51. ITT (2014) Internal team project report on microhydro plants in Nepal. ITT, TH Köln, Cologne, Germany

52. DECEEC (2006) Detailed feasibility study report of Malekhu Khola MHVEP Mahadevsthan VDC, Dhading District-volume I. DECEEC (DE Consultancy and Epsom Engineering Consultancy JV), Kathmandu, Nepal 